\title{
Critérios para autoria e avaliação de uma publicação científica
}

\author{
Criteria for authorship and evaluation of a scientific paper
}

\author{
Andy Petroianu ${ }^{1}$ \\ ${ }^{1}$ Professor titular do Departamento de Cirurgia da Faculdade de Medicina da Universidade de Minas Gerais (UFMG), Belo Horizonte, MG.
}

Recebido: 1/2/2009 - Aceito: 1/12/2009

Petroianu A / Rev Psiq Clín. 2010;37(1):1-5

\section{Introdução}

Publicar tornou-se quase obrigatório em Medicina. A sentença "publish or perish" deixou de ser apenas um trocadilho para exprimir a realidade. A contribuição social é um dos fatores que mais influenciam a credibilidade e a importância do profissional. Deve-se apontar ainda que o pesquisador é julgado pelo número de trabalhos publicados, sua qualidade e veículo utilizado em sua divulgação.

Não há dúvida quanto à importância de publicar a pesquisa, porém a ordenação de seus autores não é tarefa fácil. A falta de critérios internacionalmente aceitos levou ao estabelecimento de diversas convenções particularizadas a grupos ou setores médicos e científicos. Apenas para exemplificar, o primeiro autor pode ser o que teve a ideia, o que mais trabalhou, o orientador da investigação, o coordenador do grupo de pesquisa ou ainda o responsável pelo setor ou pela instituição onde foi desenvolvido o trabalho. Já o último autor pode ser entendido como aquele que teve a ideia, o que menos trabalhou, o orientador da investigação, o responsável pela instituição onde a pesquisa foi desenvolvida ou quem financiou o trabalho. Deve-se ainda destacar a tendência de a maioria das revistas incluir em suas referências bibliográficas apenas os três primeiros autores, deixando os demais no anonimato, independentemente de seu valor na condução do trabalho.

Outro aspecto delicado relativo à publicação científica e sua autoria refere-se à sua valorização. Desde antes de Hipócrates tem sido ressaltada a dificuldade em julgar. Avaliar uma publicação científica é complexo, principalmente quando é necessário ponderar a produção científica. Verificar o desempenho de um profissional, de uma faculdade, de um programa de pós-graduação ou de um setor de pesquisa raramente escapa à subjetividade. Não existindo padrões estabelecidos, cabe ao examinador guiar-se por opiniões pessoais decorrentes de sua experiência e sujeitas a múltiplos conflitos de interesse. Essa falta de normas pode, eventualmente, resultar em parcialidade e falta de uniformidade até dentro de uma mesma comissão examinadora. Suas consequências podem ser constrangedoras e prejudiciais tanto para os julgados quanto para os que julgam.

\section{Critérios relativos à autoria científica}

Com o objetivo de sugerir uma ordem na autoria científica, são apresentados tópicos pontuados e resumidos na tabela 1. O trabalho de cada membro da equipe será discutido, com vista a graduar sua participação e, consequentemente, incluí-lo no artigo como autor ou merecedor e agradecimento.

A principal condição para ser autor é ter participação intelectual na elaboração, condução, análise e redação do trabalho. A criatividade voltada para o avanço científico merece autoria.
Tabela 1. Pontuação para autoria de acordo com a participação no trabalho

\begin{tabular}{l|c}
\hline Participação & Pontos \\
\hline Criar a ideia que originou o trabalho e elaborar hipóteses & 6 \\
\hline Estruturar o método de trabalho & 6 \\
\hline Orientar ou coordenar o trabalho & 5 \\
\hline Escrever o manuscrito & 5 \\
\hline Coordenar o grupo que realizou o trabalho & 4 \\
\hline Rever a literatura & 4 \\
\hline Apresentar sugestões importantes incorporadas ao trabalho & 4 \\
\hline Resolver problemas fundamentais do trabalho & 4 \\
\hline Criar aparelhos para a realização do trabalho & 3 \\
\hline Coletar dados & 3 \\
\hline Analisar os resultados estatisticamente & 3 \\
\hline Orientar a redação do manuscrito & 3 \\
\hline Preparar a apresentação do trabalho para evento científico & 3 \\
\hline Apresentar o trabalho em evento científico & 2 \\
\hline Chefiar o local onde o trabalho foi realizado & 2 \\
\hline Fornecer pacientes ou material para o trabalho & 2 \\
\hline Conseguir verbas para a realização do trabalho & 2 \\
\hline Apresentar sugestões menores incorporadas ao trabalho & 1 \\
\hline Trabalhar na rotina da função, sem contribuição intelectual & 1 \\
\hline Participar mediante pagamento específico & -5 \\
\hline
\end{tabular}

Terão direito à autoria os participantes que alcançarem 7 pontos na soma dos itens em que tiverem trabalhado. Aos demais (entre 4 e 6 pontos) serão concedidos agradecimentos registrados na publicação. A sequência dos autores segue a ordem decrescente de pontuação.

\section{Criar a ideia que originou o trabalho e elaborar hipóteses}

Todo trabalho científico é oriundo de uma ideia e da busca de solução para um problema. Em várias culturas e livros religiosos é citada uma sentença que contemporaneamente Lévi-Strauss lapidou como "Sábio não é o homem que fornece as verdadeiras respostas; é o que formula as verdadeiras perguntas". Se a questão tiver sido bem formulada, ela contém em si o caminho para a resposta. Essa primeira etapa é $o$ alicerce, sem o qual o trabalho jamais existiria.

Não são raras as boas ideias que surgem até de pessoas leigas no campo de conhecimento em que teriam aplicabilidade. Conversas informais podem dar origem a temas que mereçam uma investigação científica maior. Se o dono da ideia não tiver interesse ou competência para elaborar as hipóteses e estruturar a pesquisa, ele poderá aliar-se a um grupo capaz de desenvolver a investigação. 


\section{Estruturar o método de trabalho}

A segunda etapa do trabalho, tão importante quanto a ideia, é sua estruturação. É preferível que o autor da ideia também seja capaz de desenvolvê-la, porém não há desdouro em procurar quem possa delinear a pesquisa de forma mais adequada. Esses dois primeiros tópicos, por serem os mais importantes, merecem a maior pontuação.

\section{Orientar o trabalho}

A orientação da pesquisa não deve ser entendida apenas como um relacionamento entre mestre e discípulo. Todos os pesquisadores necessitam, em determinada fase de seu trabalho, do auxílio de uma pessoa mais experiente no assunto, principalmente quando o estudo transcorrer em um campo científico no qual o investigador estiver menos afeito. Nesse caso, é aconselhável recorrer a um perito no tema. $\mathrm{O}$ valor de quem apenas orienta não pode estar no mesmo nível de quem teve a ideia ou delineou o trabalho. Todavia, como o orientador precisa participar de toda pesquisa, ele é destacado entre os autores.

\section{Escrever o manuscrito}

É indispensável que todo trabalho científico, depois de concluído, seja publicado. Não faz sentido realizar um estudo, independentemente de seu valor, e não divulgá-lo. Todo artigo contribui de alguma maneira para o progresso científico e pode auxiliar outros pesquisadores que trabalham na mesma área do conhecimento. Atualmente, há a tendência cada vez maior de publicação no idioma inglês, para alcançar divulgação internacional. Portanto, quem escreve o artigo e principalmente ao traduzi-lo para o inglês merece uma pontuação maior, com vista à sua inclusão destacada entre os autores.

\section{Coordenar o grupo que realizou o trabalho}

A função de coordenar o grupo que está desenvolvendo a investigação é muito importante, pois é papel do líder aglutinar os membros da equipe e colocá-los nas funções que lhes forem mais adequadas. O entrosamento dos pesquisadores também depende desse coordenador. Pressupõe-se que ele seja experiente e capaz de enriquecer, com seu conhecimento, os trabalhos realizados pelo grupo. Portanto, mesmo não sendo indispensável ao trabalho em questão, ele faz jus à pontuação.

\section{Rever a literatura}

A revisão bibliográfica faz parte de toda pesquisa, pelos subsídios que pode trazer à elaboração do projeto e para confrontar os resultados obtidos com os previamente encontrados por outros autores. $\mathrm{O}$ estudo pode ser conduzido sem esta etapa e alcançar um bom êxito, porém corre o risco de cometer impropriedades que venham comprometê-lo e até invalidá-lo, por desconhecimento de aspectos essenciais, já descritos anteriormente.

\section{Apresentar sugestões incorporadas ao trabalho}

Em todas as fases da pesquisa surgem oportunidades para sugestões com vista ao seu aperfeiçoamento ou para facilitar sua condução. Todavia, algumas propostas colocam em risco o projeto inicial, pelas profundas modificações a ele feitas. Assim sendo, qualquer proposta de alteração deve ser analisada com cuidado, para suas repercussões não descaracterizarem ou invalidarem os resultados da investigação. Se a sugestão valorizar consideravelmente o trabalho, seu autor merece ser convidado para autoria, desde que atinja a pontuação necessária, por meio de outras atividades voltadas à pesquisa em questão.

\section{Resolver problemas fundamentais do trabalho}

Não são incomuns, durante uma investigação, impasses que colocam em risco seu desenvolvimento. Deve-se diferenciar a resolução de um problema oriundo do projeto original de propostas novas feitas a um trabalho que estava sendo conduzido sem impedimentos maiores. A solução dos obstáculos é imprescindível, sob pena de perder-se o trabalho. Quem for capaz de resolver um problema maior merece o convite para fazer parte da equipe e, eventualmente, da autoria da pesquisa.

\section{Coletar dados}

A coleta dos dados é, muitas vezes, um trabalho monótono e demorado, porém raramente envolve algum tipo de contribuição intelectual. Dessa forma, ela não requer, necessariamente, uma formação específica dentro da área de conhecimento na qual a pesquisa está inserida e, mesmo considerando a importância do esforço e da demora em colher dados, o valor de quem realizou esse trabalho é menor. Tal situação pode gerar conflito com alguns colaboradores que, apenas por terem contribuído com a coleta de dados, julgam-se no direito de serem autores principais da pesquisa. Na realidade, deve-se reforçar que, de direito, somente quem participou intelectualmente merece autoria. Os auxílios não intelectuais podem receber agradecimento. Para evitar disputas desagradáveis, essas informações precisam ser esclarecidas antes de iniciar a tarefa. Evidentemente, se o responsável pela coleta dos dados realizar outras tarefas de destaque na pesquisa, poderá até tornar-se autor principal, pela soma de atividades.

\section{Apresentação do trabalho em eventos científicos}

Muitos estudos, antes de serem publicados em revista, são apresentados como comunicações em eventos científicos. Tal procedimento é aconselhável, pois o debate em plenário com outros profissionais acompanha-se de sugestões úteis ao enriquecimento da pesquisa. Novas investigações na mesma linha também podem surgir após tais discussões.

Quem estiver envolvido no trabalho está apto a uma boa apresentação e merece um crédito coerente com essa tarefa. Contudo, ao submeter um trabalho para apresentação em evento médicocientífico, cabe observar as normas determinadas por sua Comissão Científica. Na maioria das vezes, respeita-se a ordem de autoria determinada pela equipe de pesquisadores, sublinhando o nome do apresentador. Todavia, há casos em que as normas do evento definem o primeiro autor como quem irá apresentar, mudando a ordem dos autores, apenas para essa situação especial. Esse fato não configura desrespeito com os demais membros da equipe, desde que todos estejam de acordo com essa mudança transitória. Autoria em anais de congresso tem pouco valor, pois o trabalho não foi previamente julgado quanto ao seu mérito.

\section{Chefiar o local do trabalho e conseguir verbas}

O fato de ser chefe e ainda participar dos trabalhos é digno de ser valorizado. O mérito está no poder aglutinador e no incentivo que sua presença trabalhando é para os demais membros da equipe. A ele também cabe adequar a infraestrutura às necessidades das equipes e obter recursos financeiros. Todavia, sua contribuição precisa ser também intelectual, pois, de outro modo, seu trabalho torna-se apenas de técnico na função.

\section{Fornecer pacientes ou material}

Em Medicina, muitas pesquisas são realizadas com doentes. Não é necessário que o médico avalie apenas seus próprios enfermos; ele poderá também investigar em prontuários de pacientes cadastrados em um serviço, hospital ou ainda solicitar a permissão de colegas para conduzir o trabalho em seus doentes. Se os pacientes ou os prontuários forem estudados, seguindo os princípios éticos, normatizados em diversos códigos, não haverá empecilho maior no relacionamento entre pesquisador, paciente e seu médico. Quando apenas um ou poucos médicos fornecerem seus doentes para o estudo, cada um desses profissionais terá direito a agradecimento registrado na publicação. Por outro lado, se for estudada alguma conduta propedêutica ou de 
tratamento criada ou adotada especificamente por um determinado profissional, ele passa a exercer o papel de quem criou a ideia utilizada no trabalho e será valorizado com a maior pontuação.

\section{Trabalhar na rotina da função}

Muitas investigações dependem da colaboração de profissionais que, ao atuarem em suas funções, podem auxiliar na pesquisa. Entre eles, destacam-se médicos, enfermeiros, psicólogos, fisioterapeutas, assistentes sociais, técnicos de laboratório, secretários, bibliotecários e assim por diante. Cada um pode ter colaborado com o estudo, entretanto seu auxílio restringe-se ao desempenho em sua rotina de trabalho, eventualmente direcionado a uma solicitação específica e transitória. Na maioria das vezes, eles não se envolvem com a pesquisa e sequer a conhecem. Portanto, apenas por essa função, não há mérito para autoria.

\section{Participar mediante pagamento específico}

Toda atividade científica pressupõe um ideal maior e não condiz com a remuneração monetária específica a ela. É evidente que os pesquisadores têm obrigações individuais, familiares e sociais mediadas pelo dinheiro e precisam ser pagos adequadamente para sua sobrevivência digna, bem como a de seus dependentes, dentro dos padrões pressupostos para seu nível social e intelectual. Contudo, os recursos recebidos sob forma de salário, honorário ou bolsa não devem ser por um trabalho específico, mas pela atuação profissional e científica. De acordo com esse pressuposto, seria estranho algum membro da equipe solicitar pagamento por contribuir na pesquisa. Caso seja importante para o trabalho a participação de determinado profissional e ele solicitar pagamento por seu auxílio, o grupo deve arcar com esse custo. Contudo, a participação no trabalho, sob pagamento, desabona na concessão de autoria.

\section{Critérios para ordenar os autores}

Existem várias regras para estabelecer a ordem dos autores de determinado trabalho. Muitos grupos de pesquisa possuem normas próprias, nas quais há perfeita harmonia. Não é prudente alterar esse equilíbrio, principalmente após iniciar o trabalho, sob pena de criar conflitos que coloquem em risco a própria integração da equipe. O melhor é deixar claro e de comum acordo os princípios objetivos a serem seguidos para autoria, antes de iniciar o trabalho. Qualquer imposição é deplorável, especialmente se vier de um superior com poder sobre os demais.

No critério aqui proposto, cada membro da equipe recebe os pontos correspondentes aos itens em que tiver participado. Não há limite para o número de pesquisadores de cada etapa do trabalho. A cada participante será concedida a soma dos valores das etapas em que tiver contribuído. Se houver dúvida, ela deverá ser discutida em grupo, até chegar a um acordo. No empate de pontuação, considera-se a sequência dos itens da tabela 1. Aquele que tiver obtido pontos em item de mais valor ficará à frente dos demais. Os autores são posicionados em ordem decrescente de pontuação até o valor mínimo de sete. Quem obtiver valor inferior a sete poderá receber agradecimento, mas não será incluído na autoria do artigo científico.

\section{Autor honorário}

Finalizado o trabalho, os pesquisadores podem decidir conceder, de forma incorreta, autoria a uma pessoa alheia à pesquisa. $\mathrm{O}$ autor honorário é a maneira mais comum de autoria inapropriada. Entre as circunstâncias que levam a tal atitude estão:

- homenagear alguém importante na vida pessoal, profissional ou científica de um ou mais membros da equipe;

- homenagear alguém que, de alguma maneira, esteja ligado ao trabalho realizado, mesmo sem participação direta nele, como, por exemplo, o autor de uma determinada técnica;
- incluir entre os autores um nome de notoriedade científica, social ou ligado à revista na qual se deseja publicar o trabalho, com vista a um trânsito mais fácil para a publicação;

- retribuir a gentileza feita previamente por um determinado pesquisador em relação à equipe que conduziu o trabalho, por exemplo, tendo concedido autoria indevida a membros da equipe, sem que eles tenham participado da outra pesquisa;

- permitir a inclusão de um colega com dificuldade profissional, em decorrência de sua baixa produção científica etc.

O autor honorário é convidado e seu nome somente pode constar na autoria do trabalho após sua aprovação explícita, de preferência, por escrito, pois, uma vez incluído, esse autor será também responsável pelo conteúdo do trabalho. Portanto, ele somente deverá aceitar essa "honra" após analisar muito bem o manuscrito e certificar-se da verdade de todas as informações nele contidas.

\section{Usurpar a autoria principal}

Quando alguma pesquisa tem a potencialidade de provocar um impacto maior na comunidade científica ou na sociedade, existe a tendência de seus responsáveis desejarem assumir a autoria principal do trabalho. Tendo em vista que as investigações são, geralmente, o resultado da contribuição de vários pesquisadores, é natural cada membro da equipe considerar sua parte como sendo a mais importante. $\mathrm{O}$ impasse criado pode colocar em risco a própria publicação e comprometer o relacionamento dentro do grupo de pesquisa.

Outra situação, mais comum e menos elegante, ocorre quando o colaborador sabe que sua contribuição foi menor, mas, diante da importância do trabalho, sobrepõe-se aos demais membros da equipe, valendo-se de poder financeiro, político ou até científico, sem levar em conta normas éticas. A dimensão desse fato é identificada no cotidiano, não somente entre pesquisadores, mas em toda a sociedade. Lamentavelmente, é difícil evitar ou corrigir essa situação vergonhosa.

\section{Agradecimentos}

O tópico de agradecimentos é o mais elegante do artigo publicado e mostra a boa índole dos autores, que souberam externar sua gratidão a quem os auxiliou. Em algumas situações, o agradecimento é obrigatório, como no caso das fontes que patrocinaram o trabalho e do local em que a pesquisa foi desenvolvida, caso ela não se tenha desenrolado no ambiente de trabalho próprio de seus autores. Nesta última condição, o nome do local já está incluído na apresentação dos autores. Caso a pesquisa seja realizada com doentes ou prontuários de instituições alheias à de origem dos autores, torna-se obrigatória a menção desses locais neste tópico.

A maior parte dos trabalhos traz agradecimentos adequados, porém alguns autores exageram, com número excessivo de menções. Essa atitude, além de ser imprópria, deprecia os que de fato mereceram o reconhecimento.

No caso de uma tese ou monografia, é usual e de bom alvitre colocar nas páginas iniciais uma grande lista de agradecimentos. Nessa oportunidade, é pertinente estender-se a lista de nomes até para quem deu contribuição menor, porém, necessariamente, ela precisa ser específica ao trabalho em questão, caso contrário pode entrar no tópico de dedicatórias. Todavia, ao transformar a tese em artigo de revista, essa lista restringe-se aos colaboradores indispensáveis.

Não existe um princípio estabelecido para orientar os autores quanto aos nomes que devem ser incluídos neste tópico. Talvez possa ser utilizada a tabela 1 para quantificar esse mérito e se conceda agradecimento a quem tiver obtido entre quatro a seis pontos.

\section{Avaliação do trabalho científico}

O pesquisador e a instituição devem ser julgados pela autoria do trabalho, pelo tipo de publicação e pelo valor do veículo de divulgação. $\mathrm{O}$ critério de avaliação tem por base o julgamento quantitativo dos diversos fatores envolvidos na pesquisa científica publicada. 


\section{Posição do autor na lista de autoria}

Para facilitar e tornar menos subjetivo o julgamento da autoria, foi considerada a soma de pontos de todos os autores como sendo 15. A tabela 2 exibe uma proposta para quantificar o valor de cada posição do pesquisador na autoria do trabalho.

Tabela 2. Pontuação (entre parênteses) de acordo com o número de autores do trabalho e a posição de cada um deles

\begin{tabular}{|c|}
\hline Autor único - (15) \\
\hline 2 Autores - $1^{\circ}(9) ; 2^{\circ}(6)$ \\
\hline 3 Autores $-1^{\circ}(7) ; 2^{\circ}(5) ; 3^{\circ}(3)$ \\
\hline 4 Autores - $1^{\circ}(6) ; 2^{\circ}(4) ; 3^{0}(3) ; 4^{0}(2)$ \\
\hline 5 Autores $-1^{0}(5) ; 2^{\circ}(4) ; 3^{0}(3) ; 4^{0}(2) ; 5^{\circ}(1)$ \\
\hline 6 Autores $-1^{0}(5) ; 2^{0}(3) ; 3^{0}(2) ; 4^{0}(2) ; 5^{0}(2) ; 6^{0}(1)$ \\
\hline 7 Autores $-1^{0}(5) ; 2^{0}(2) ; 3^{0}(2) ; 4^{0}(2) ; 5^{0}(2) ; 6^{0}(1) ; 7^{0}(1)$ \\
\hline 8 Autores - $1^{\circ}(5) ; 2^{0}(2) ; 3^{0}(2) ; 4^{0}(2) ; 5^{0}(1) ; 6^{0}(1) ; 7^{0}(1) ; 8^{0}(1)$ \\
\hline 9 Autores - $1^{0}(5) ; 2^{0}(2) ; 3^{0}(2) ; 4^{0}(1) ; 5^{0}(1) ; 6^{0}(1) ; 7^{0}(1) ; 8^{0}(1) ; 9^{0}(1)$ \\
\hline 10 Autores - $1^{\circ}(5) ; 2^{0}(2) ; 3^{0}(1) ; 4^{0}(1) ; 5^{\circ}(1) ; 6^{0}(1) ; 7^{0}(1) ; 8^{0}(1) ; 9^{\circ}(1) ; 10^{\circ}(1)$ \\
\hline 11 Autores - $1^{0}(4) ; 2^{0}(2) ; 3^{0}(1) ; 4^{0}(1) ; 5^{\circ}(1) ; 6^{0}(1) ; 7^{0}(1) ; 8^{0}(1) ; 9^{0}(1) ; 10^{0}(1) ; 11^{0}(1)$ \\
\hline 12 Autores ou mais - $1^{\circ}(3) ; 2^{\circ}(2) ;$ do $3^{0}$ para trás (1) \\
\hline
\end{tabular}

\section{Autor único}

Tendo em vista que na padronização do presente critério a soma das autorias foi definida como sendo 15 , quando um único autor tiver produzido o trabalho, ele merece receber o valor integral desses pontos.

\section{Dois autores}

Entre dois autores, é razoável atribuir ao primeiro um valor cinquenta por cento superior ao segundo. Dessa maneira, para manter coerente a padronização quantitativa, a diferença deve ser mantida mesmo quando houver mais autores.

\section{Maior número de autores}

Existem muitas formas de ordenar os autores e é muito difícil saber o critério utilizado para essa distribuição, conforme foi mostrado na primeira parte deste artigo. Na padronização aqui apresentada, optou-se por manter a ordem decrescente de valor entre o primeiro e o último autor. Caso o examinador saiba que a equipe ordenou os autores por um critério diferente, ele deverá adaptar os valores propostos para a autoria à sequência decrescente por mérito relativo ao trabalho realizado e não pela ordem encontrada no artigo.

Os pontos atribuídos ao primeiro autor ou ao autor mais importante para o trabalho são maiores e a diferença entre ele e os demais seguirá uma constante até quando houver cinco autores. A partir desse número, são concedidos valores idênticos para os autores mais afastados do primeiro.

\section{Qualificação do trabalho}

Existem grandes diferenças entre os tipos de trabalho realizados, portanto sua pontuação também deve ser particularizada de acordo com seu valor para a comunidade científica à qual se destina. Diante dessas controvérsias encontradas na literatura, decidiu-se pela proposta de pontuação apresentada na tabela 3. Por esse critério estão inseridos os tipos de divulgação do trabalho e seus respectivos valores.

A apresentação em evento científico atinge um público muito restrito e seus conhecimentos são, geralmente, muito fugazes na memória de quem os assiste. É muito rara a consulta aos anais ou mesmo a suplementos de revista que contenham resumos de congressos, para buscar subsídios a qualquer trabalho científico. Por outro lado, sabendo que a divulgação em eventos é quase livre de pré-julgamentos, muitos estudos sem critério científico e até mesmo condenáveis sob vários aspectos podem vir a ser expostos. Assim sendo, esse tipo de publicação receberia a menor pontuação.

Uma exceção deve ser feita com respeito à Nota Prévia, que é aprovada pela comissão científica e por um presidente de mesa do evento. Tratando-se, por princípio, de uma informação inédita e que pode ter grande valor, ela é apresentada para preservar a autoria de seu criador antes dos trâmites para uma publicação maior em uma revista. Portanto, essa forma de divulgação merece ser destacada com uma pontuação mais elevada.

Quanto às publicações em revista, elas devem receber uma pontuação superior, pois mesmo as Cartas ao Editor passam por um julgamento editorial antes de serem aprovadas.

Tabela 3. Pontuação de acordo com o tipo de publicação 9,11,14,20

\begin{tabular}{l|c}
\hline Evento médico científico & Pontos \\
\hline Comunicação em evento científico sem publicação em anais & 1 \\
\hline Comunicação em evento científico com publicação em anais & 2 \\
\hline $\begin{array}{l}\text { Comunicação em evento científico com publicação em suplemento } \\
\text { de revista }\end{array}$ & 3 \\
\hline Comunicação de nota prévia & 10 \\
\hline Revista & Pontos \\
\hline Carta ao editor & 10 \\
\hline Relato de caso & 20 \\
\hline Comunicação curta & 30 \\
\hline Apresentação de casuística & 30 \\
\hline Editorial & 30 \\
\hline Comentários & 30 \\
\hline Apresentação de método ou de técnica operatória original & 40 \\
\hline Revisão de literatura ou de livro, sem contribuição pessoal & 40 \\
\hline Apresentação de uma hipótese & 40 \\
\hline Revisão de um tema com contribuição pessoal & 50 \\
\hline Trabalho de pesquisa clínica ou experimental completo & 70 \\
\hline Qualquer tipo de artigo que altere um conceito estabelecido & 90 \\
\hline
\end{tabular}

\section{Qualificação da revista}

Avaliar o autor e a instituição por seu trabalho é menos difícil do que ponderar a qualificação da revista. Esse valor não seria complicado se fosse levado em conta apenas o "fator de impacto" da revista em que o artigo foi publicado. Contudo, são notórios os seguintes aspectos:

- há muitos artigos excelentes publicados em revistas de menor impacto ou que não estão incluídas em Base de Dados reconhecida internacionalmente;

- grande parte dos artigos publicados em revista com impacto maior é passível de críticas severas por sua baixa qualidade e por ter sido aceita devido a interesses alternativos, sem relação com seu valor científico;

- há preconceito estabelecido em muitas revistas com impacto elevado em relação a artigos provenientes de locais considerados menos desenvolvidos cientificamente, como é o caso dos países latino-americanos, os da África e de parte da Ásia;

- há bloqueio difícil de ser transposto à inclusão de novas revistas dentro das Bases de Dados reconhecidas e, consequentemente, a elas é negado o "fator de impacto". Mesmo após sua inclusão na Base de Dados, muitas revistas permanecem sem "fator de impacto" ou com "fator" muito reduzido.

Outro aspecto a ser ponderado refere-se ao público específico a que se dirige cada trabalho realizado. Dessa forma, os autores precisam escolher o periódico mais adequado para atingir essa população. Há pesquisas que interessam apenas à pequena comunidade na qual foram produzidas; outras podem ter alcance municipal ou regional; 
já a maioria é voltada para uma divulgação nacional e, se possível, internacional. Não se deve considerar que uma investigação de alcance mundial seja mais bem feita ou que tenha mais valor do que outra voltada a interesses comunitários específicos. Seria desejável a análise do trabalho por suas qualidades intrínsecas e não pelo seu alcance em quantidade de público ao qual ele é direcionado, porém essa meta ainda está longe de ser alcançada.

\section{Pontuação pelo valor da autoria}

Uma vez estabelecidos os pontos de cada um dos itens, com o auxílio das respectivas tabelas, a pontuação final é dada pelo produto de cada um desses fatores. Assim, multiplicam-se os pontos da posição do autor pelos pontos do tipo de publicação. Multiplica-se esse produto pelo fator de impacto da revista.

Considerando que os fatores de impacto variam entre zero e várias dezenas, sendo que a maioria situa-se abaixo de um ponto, não se pode aplicar a multiplicação simples, pois todas as publicações em revistas com fator de impacto menor de um ponto seriam prejudicadas. Assim, sugere-se que o menor fator de impacto a ser atribuído a cada veículo de divulgação, indexada ou não, seja 0,1 , mesmo para aqueles que estiverem abaixo desse valor ou que não tenham classificação. Em seguida, o fator de impacto é multiplicado por 10 e esse resultado será levado em conta para a multiplicação com o produto obtido pela posição do autor e tipo de publicação.

\section{Conclusões}

Observa-se, pelo presente artigo, a complexidade que gira em torno dos critérios para avaliar a publicação de um trabalho científico. Este é um assunto muito delicado, sendo necessários cuidado e muita seriedade, pois envolve o nome de um pesquisador e, por trás dele, todos os valores individuais, como honra, princípios morais, credibilidade, respeito, interesses, padrões de conduta, ideais e assim por diante. É importante reforçar que, para prevenir conflitos maiores, o grupo que se dispõe a realizar um trabalho científico e as comissões responsáveis por julgá-los devem estabelecer no início, da forma mais objetiva possível, os critérios que serão adotados para distribuição da autoria e sua avaliação. Os tópicos abordados refletem os pontos de vista do autor, com base na literatura e vivência científica pessoal. Esses critérios evitam interferências subjetivas e previnem conflitos de interesse. Entretanto, cabe ao leitor meditar sobre os valores apresentados e seguir a conduta que lhe parecer mais correta e honesta. 